$\mathbb{H}_{\text {ปisgei }} \mathcal{A}$

ISSN: 1983 2435

\title{
Periquillo Sarniento: uma narração da educação como obstáculo à autonomia
}

\section{Periquillo Sarniento: the description of education as an obstacle to autonomy}

\author{
Periquillo Sarmento: una narración de la educación como \\ obstáculo a la autonomía
}

\author{
Otília Maria Alves da Nóbrega Alberto Dantas * \\ otiliadantas@gmail.com \\ Universidade de Brasília (UnB) \\ Angélica Gisele Melo Silva* \\ giselemeolo@gmail.com \\ Universidade de Brasília (UnB)
}

RESUMO: Periquillo Sarniento, obra de José Joaquim Fernández de Lizardi, foi escrita com o intuito de denunciar à sociedade a educação então vigente (inicio do século XVIII) e o seu impacto individual e social. Este trabalho, de natureza bibliográfica, visa compreender as denúncias do autor no âmbito da educação, principalmente no que confere ao desenvolvimento da autonomia e ao seu impacto no indivíduo e no meio social. Metodologicamente, utilizou-se a análise do discurso, juntamente aos aportes teóricos de grandes pensadores da educação. Os resultados indicam que os discursos presentes no romance apontam não só para a importância da autonomia exógena, construída sobre a exterioridade do sujeito sob a tutela da educação, mas também para a dificuldade de professores e alunos em lidar com o meio justamente pela falta de autonomia, uma vez que são herdeiros de uma educação analógica, mecanicista e heterônoma, que lhes dificultou o desenvolvimento de reflexões e atitudes e que impacta não apenas o indivíduo, mas também a sociedade, terminando, com isso, por favorecer o status quo. A importância do estudo deve-se ao fato de que esses discursos abrangem toda a educação de um estudante e mostram como ela afeta sua vida pessoal e social, o que oportunizou pensar sobre esta educação e em maneiras de modificar a nossa, pois embora a obra seja antiga, as críticas são atuais.

Palavras-chave: Educação. Literatura. Autonomia. Sociedade.

ABSTRACT: Periquillo Sarniento, a novel by José Joaquim Fernández de Lizardi, was written with the goal of denouncing education to the society at the time (beginning of the 18th century) and its individual and social impact. This work, of bibliographical nature, aims to understand the author's complaints about education,

\footnotetext{
Doutora em Educação pela Universidade Federal do Rio Grande do Norte e professora da Universidade de Brasília

Graduanda de Letras-Língua Espanhola e Literatura Espanhola e Hispano-americana pelo Instituto de Letras da Universidade de Brasília
} 
especially about the development of autonomy and the impact on individuals and their social environment. Methodologically, it is based on discourse analysis and on theoretical contributions of great education thinkers. The results show that the discourses present in the novel point not only to an exogenous autonomy, since it is built on the subject's exteriority under the guidance of education, but also that teachers and students have difficulty in dealing with the social environment precisely because of their lack of autonomy, since they are heirs of the analogical, mechanistic and heteronomous education, which makes it hard for them to prompt reflections and attitudes and impacts individuals and society, thereby favoring the status quo. The significance of this study is due to the fact that these discourses are related to students' whole education and show how it affects their personal and social life, making it possible to reflect upon the education presented in the novel and ways of modifying ours, because even though this work is old, its criticisms are current.

Keywords: Education. Literature. Autonomy. Society.

RESUMEN: Periquillo Sarmento, obra de José Joaquim Fernández de Lizardi fue escrita con el fin de denuncia a la sociedad la educación de aquel momento (inicio del siglo XVIII) y su impacto individual y social. El artículo, de naturaleza bibliográfica, buscó comprender las denuncias del autor en la educación, principalmente cuando impacta al desarrollo de la autonomía, el individuo y el medio social. Metodológicamente, se utilizó el análisis del discurso juntamente con las aportaciones teóricas de grandes pensadores de la educación. Los resultados apuntan que la autonomía es exógenos, pues se construye en la exterioridad del sujeto bajo la educación; profesores y estudiantes tienen dificultades en lidiar con el medio, justamente por su falta de autonomía, una vez que son herederos de una educación analógica, mecanicista y heterónoma, que dificulta el desarrollo de la reflexión y actitudes y no tiene impacto solo en el individuo sino también en la sociedad, favoreciendo así el status quo. La importancia del estudio se debió al hecho de abarcar toda la educación de un estudiante y enseñar cómo ella afecta a la vida personal y social, lo que nos permitió pensar acerca de la educación y en medios para modificar la nuestra, pues, aunque, la obra sea antigua, las críticas son actuales.

Palabras-Clave: Literatura. Educación. Autonomía. Sociedad.

\section{Introdução}

Lei da inércia: Todo corpo permanece em seu estado de repouso, ou de movimento uniforme em linha reta, a menos que seja obrigado a mudar seu estado por forças impressas nele (NEWTON apud PONCZEK, 2009, p. 97).

A literatura, nos seus primórdios, foi criada para educar reis e príncipes (VASCONCELOS, 2006, p. 71). Com o passar dos séculos e o advento da imprensa, tornou-se veículo de denúncia, principalmente dos males que se passavam na sociedade. Em diversos momentos, abriu caminho para outras possibilidades, sendo uma delas o diálogo entre a denúncia e a educação, pois, diante de diversos 
abusos, a sociedade, por vezes, se levantou conclamando mudanças, quebrando a inércia que tem tolerado no decorrer dos tempos. Não foi por menos que um deputado aliado à ditadura de Franco deixou esta frase sobre o poeta Federico García Lorca: "Mais perigoso com a caneta do que muitos com o revólver" (VARGAS, 2009, p. 125-126).

Nesse contexto, destacamos José Joaquim Fernández de Lizardi (17761827), escritor e jornalista mexicano. Foi considerado o iniciador do romance moderno da América. Em 1812 fundou o jornal liberal El Pensador Mexicano, suspenso pelo governo de Fernando VII. Tecia críticas veementes contra a ordem política, militar e eclesiástica constituída. Depois da Independência, dirigiu o Diário do Governo (1825). Suas obras narrativas que refletem as suas posições críticas incluem: Periquillo Sarniento (1816 e 1830-1831) e La Quijotilla y su prima (1818), dentre outras. Também cresceu, embora com menos sucesso, na poesia e no teatro. Lizardi criticou as falhas administrativas e morais do império espanhol, com especial ênfase para os problemas da Nova Espanha. Para ele, a reforma somente era possível pela educação racional, universal e obrigatória e discussão livre de ideias. Lizardi tornou-se conhecido pelo trabalho de cunho político, literário, jornalístico, sociológico, historiográfico e linguístico. Rejeitado pelos separatistas e odiado pelos conservadores, morreu na pobreza em 21 de Junho de 1827, vítima de tuberculose. No seu epitáfio se lê: "Aqui jaz o pensador mexicano que fez o que pôde para a sua pátria" (GARCíA, 2016).

Este artigo visa compreender as denúncias de Lizardi no âmbito da educação, principalmente no que confere ao desenvolvimento da autonomia e ao seu impacto no indivíduo e no meio social. Para tanto, toma como referência a sua obra Periquillo Sarniento (2001a; 2001b) - primeiro romance escrito na América Latina e composto de 4 tomos, dos quais analisamos os dois primeiros, além dos aportes teóricos de Vigotski (2011), Freire (2011; 2013), Rancière (2003), Contreras (2002), dentre outros.

Lizardi nos apresenta Pedro Sarniento, vulgo Periquillo Sarniento, desde o berço até a terceira idade. O principal objetivo do autor nesta obra foi denunciar os problemas educacionais e o seu impacto no meio social. Lizardi acreditava que, a partir da modificação da educação para o desenvolvimento da autonomia do aluno, a sociedade se levantaria, não aceitando mais os males que sofrera, logrando o que era o seu desejo e da população mexicana: a independência de seu país. A obra, 
assim, não foge a esses objetivos, promovendo diferentes possibilidades: denuncia os falhos da sociedade ao mesmo tempo em que a aconselha a não seguir determinados caminhos.

Poderemos, quiçá, ser julgadas ingênuas ao fazer uso da literatura para esse objetivo, uma vez que existem tantos campos empíricos. Entretanto, salvaguardamonos, explicando que a obra açambarca a vida do protagonista desde seu berço familiar até a sua velhice, o que nos dá a oportunidade de pensar em toda a influência da educação na vida do indivíduo. Valemo-nos, ainda, do desejo de provocar um diálogo com os autores citados por legitimarem, em suas obras, a importância dos temas abordados neste estudo, principalmente Vigotski um dos autores standard para compreender a obra em tela. Supondo ainda não ser suficiente a veracidade de tais argumentos, apropriamo-nos do pensamento russo para tal:

Um traço particular da intelligentsia russa era a importância que dava à literatura, que vai não apenas como a personificação suprema da cultura, mas também como a mais concentrada forma de vida. Os personagens literários eram julgados [...] como tipos psicológicos e sociais reais, ao passo que debates políticos e históricos eram comumente conduzidos na forma de literatura e em torno da literatura (KOZULIN apud DANIELS, 2003, p.40).

Explicado o nosso material de pesquisa, cabe-nos atentar que este trabalho estuda dois dos quatro tomos da obra de Lizardi (2015a; 2015b). No entanto, os referidos tomos possuem tamanha magnificência em torno da educação que foi o suficiente para estudar o personagem principal desde o seu berço familiar até sua vida adulta e social.

\section{Educando um pícaro ${ }^{1}$}

Com base na análise do discurso feita sobre a obra, podemos identificar que um dos objetivos do autor foi apontar como a educação pode favorecer o

\footnotetext{
${ }^{1} \mathrm{O}$ termo 'pícaro' tem uma especificidade nos estudos de Literatura. Numa perspectiva de estudos literários, "Pícaro" é uma personagem-tipo dos romances e novelas dos séculos XVII e XVIII (ainda que surgido no século XVI), caracterizado principalmente como de baixa condição, astuto e engenhoso (VICENTE, 2016). Para o dicionário online Priberam, significa inclusive: "Falto de honra e de vergonha, patife, velhaco, malicioso, astuto, que com arte e dissimulação logra o que deseja, ridículo" (PRIBERAM, 2016).
} 
desenvolvimento de um pícaro, e que esse desenvolvimento se deve à ausência de sua autonomia. Não é por menos que o autor nos apresenta, como ponto de partida, a vida do personagem na infância dentro do seio familiar. Periquillo Sarniento, cujo nome verdadeiro é Pedro Sarmiento, por uma burla ganhou esse apelido: era filho único e talvez por isso tenha sido tratado com tantos mimos, conforme destacaremos adiante.

Periquillo cresceu mimado e superprotegido tanto pelos pais como pelos seus familiares. Sequer deixavam que tivesse qualquer contato fora de casa, pois temiam que adoecesse. Se ele criava intriga com alguma empregada, acusava-a, e logo sua mãe a repreendia. Assim, aprendeu a mentir. De manhã, para ir à escola, seus próprios pais o vestiam enquanto dormia.

Buscando compreender o nosso personagem, logo recordamos o pensamento de Vigotski, principalmente neste caso, quando ressalta o caráter histórico do ser humano, principalmente no que se refere ao pensamento da criança, pois "[...] para a criança pequena, pensar significa lembrar-se" (DANIELS, 2003, p. 28). No entanto, as lembranças não agem sozinhas, pois trazem recordações resultantes de determinadas ações. Sendo assim, as ações de Periquillo, o personagem principal, eram reflexos das lembranças de sua infância. Infere-se, portanto, que a personalidade dele se formou não apenas pelas recordações de suas ações, mas destacadamente pela sua história.

Logo, fica clara a crítica de Lizardi (2015a, p. 33) quanto à permissividade dada pelos pais ao filho, principalmente quando Sarmiento destaca: "[...] vivi como um mero animal, sem saber o que importava saber" ${ }^{2}$. Evidencia-se, durante a narração, que essa é uma das principais características daquilo que o personagem se tornará no decorrer da obra.

Essa permissividade, ilustrada por Lizardi, relaciona-se àquele que permite, que é muito tolerante. Em outras palavras, esta expressão, para o autor, apresenta uma marca pejorativa, tendo em vista que se trata do excesso de liberdade dado pelos pais a Periquillo, transformando-o num ser indisciplinado que não respeita a autoridade. Sobre isto encontramos em Freire (2013) que o homem necessita lidar com o impacto da autoridade para desenvolver a sua própria autonomia. Para Contreras (2002), a autoridade deve estar consolidada, em si mesma, pela

\footnotetext{
${ }^{2}$ Todas as citações da obra do Lizardi foram traduzidas pelas autoras.
} 
necessidade que o meio apresenta. Segundo Bernstein, citado por Daniels (2003), o alimentador de grande parte dos males é o fato de pais e professores estarem preocupados apenas com o ensino exclusivo dos conteúdos escolares.

Estes estudiosos nos fazem compreender que a permissividade dada pela família e a escola a Periquillo impede que ele compreenda o sentido de autoridade. Com isto, não o ensina a ajustar o que aprendeu, a comportar-se e a se inserir no meio social, o que na concepção de Lizardi, demonstrada por meio desta "educação familiar" proposta na obra em tela, acaba disseminando problemas não apenas para pais e mestres, mas também para a sociedade e o próprio indivíduo.

Lizardi reivindica uma educação que conduza o sujeito a perceber o sentido da autoridade para sua formação. Todavia, não se trata de autoritarismo, mas um sentido de autoridade capaz de fomentar, no sujeito, pela construção do conhecimento, um comportamento autônomo e emancipado. Sobre isto, Rancière (2003) afirma que, para se chegar à autonomia da própria aprendizagem, é necessário o interesse ou o desafio imposto pela autoridade, traço que nos pais de Periquillo não encontramos e não há tampouco sinal de fomentá-los.

\section{Vida escolar}

Esperava-se que a escola fosse o local mais propício para que Periquillo desenvolvesse a sua autonomia, dado o caráter criador da escola: transformar homens em cidadãos. Um espaço, no dizer de Freire (2011), propício ao pensar, agir, criar e refletir. Para Vigotski (2011), é na escola que o pensamento da criança, pela participação com os outros no desenvolvimento de sua cognição, transforma-se de empírico para científico, o que acaba desenvolvendo, simultaneamente, várias capacidades valorizadoras da autonomia.

No entanto, isto não ocorreu com Periquillo. Seu primeiro professor era bastante permissivo e inadequado à profissão, dado o seu constante desconhecimento dos conteúdos que ensinava. Buscando identificar os erros desse professor nas obras dos pensadores, encontramos Freire (2013), que nos lembra que o aluno precisa de autoridade para alcançar a sua liberdade e para tornar-se responsável pela busca do seu próprio saber. O não domínio sobre o conteúdo é um agravante para o mestre, pois ele deve sempre atualizar-se. Já Vigotski (2011) nos adverte que o professor age como um mediador da aprendizagem do aluno, 
ajudando-o a construir conhecimentos a partir da concepção de um aluno que já o possui. Daí a necessidade de o professor saber o que ensina. No entanto, Rancière (2003) nos apresenta um novo tipo de professor: aquele que sabe provocar, no aluno, a vontade de aprender, pois dada essa vontade, o próprio aluno, a partir dos seus conhecimentos já obtidos, pode fazer uso de sua aprendizagem. Logo, o professor influencia o aluno a fazer uso do que já sabe para construir novos conhecimentos, alimentando o desenvolvimento da autonomia do estudante.

Entrelaçando o pensamento de Vigotski ao de Rancière, podemos rematar que a ideia deste último é que a vontade de aprender possui tamanha força que ela é a própria mediadora da aprendizagem, inquirindo sobre o que o aluno já sabe e levando-o a refletir autonomamente. Em nossa concepção, a vontade de aprender age como mediadora no ponto em que motiva o aluno dizendo "continua; olha o que você já fez e o que pode fazer se aplicar a mesma inteligência que já utilizou" (RANCIĖRE, 2003, p. 31).

Comparando o romance ao contexto de Rancière (2003), compreendemos que a principal falha do professor de Periquillo não era o desconhecimento do conteúdo, mas a não provocação, no aluno, da vontade de aprender, porque ao fim e a cabo importa mais que o aluno reflita, compare e descubra do que o professor saiba.

Não se adequando à cultura da primeira escola, Periquillo passa a frequentar outra instituição. Desta vez com um professor que, em nada, recorda o outro: não é permissivo, muito pelo contrário, e conhece bem o conteúdo; no entanto, era rígido: estressava-se, punha-se a gritar com os alunos e a castigá-los. Logo, nosso protagonista manteve-se aprendendo mais com as más influências dos seus amigos do que com o professor. Temos então a denúncia de que gritos e castigos não são forças boas o bastante para modificar alguém, inclusive afasta o aluno do conhecimento e do professor (MORALES, 2009). E Periquillo "tudo errava, não por falta de dedicação, e sim por sobra de medo" (LIZARDI, 2015, p. 25).

O professor, ao ser rígido e "apelar" a castigos, tende, na verdade, a afastar os alunos e a impedir que eles se sintam à vontade para expor seus erros e para arriscar-se no desconhecido, causando um enrijecimento do aluno e o seu não desenvolvimento cognitivo, pois ele apenas "aprende" por medo, como nos mostra Periquillo, acabando por passar por outros problemas. Na obra, por exemplo, o aluno, ao sair da escola, afasta-se dos estudos. 
Mudando uma vez mais de professor, este the esclareceu o que estava acontecendo com o anterior: "o açoite, meu filho, foi inventado para castigar enfrentando o racional e para avivar a preguiça do bruto que carece de razão" (LIZARDI, 2015, p. 44). Para Pimenta (2012), a reflexão, o apoio teórico e a constante atualização do professor são fundamentais para que não ele aja apenas pela memória dos seus antigos professores ou pelo o que pensa ser o correto.

Neste sentido, aquele professor que agia por repetição, gritava com os alunos e os castigava por ser a maneira de agir mais acessível a ele demonstrava a pequenez de seu conhecimento. Por não saber como lidar com certas situações, fazia uso, exclusivo, da experiência sem reflexão. A este respeito encontramos em Vigotski, citado por Daniels (2003, p. 43):

O trabalho do professor é particularmente complexo porque, em primeiro lugar, deve estar bem orientado para as regularidades da atividade pessoal da criança, ou seja, conhecer a psicologia da criança; em segundo, o professor deve conhecer as dinâmicas sociais particulares do cenário social da criança; e, em terceiro, deve saber sobre as possibilidades de sua própria atividade pedagógica para usá-las com sensibilidade e, assim, elevar a um novo nível a atividade, a consciência e a personalidade de seus pupilos.

Certamente seu professor gritava com Periquillo para que refletisse e não voltasse a errar, mas, segundo Morales (2009), atitudes violentas apenas tendem a alimentar a indisciplina do aluno e a resolvê-la momentaneamente. Este professor não refletia sobre suas ações, o que denuncia uma vez mais a sua falta de reflexão e conhecimentos pedagógicos.

$\mathrm{Na}$ terceira escola, com o bom contato com o seu professor e o bom caráter dos seus colegas, Periquilo reconhece que mesmo ainda possuindo um péssimo caráter, com este novo professor, ele se comportaria bem por ele ser digno de respeito, como afirma:

Estavam as minhas paixões sufocadas, não mortas: minha perversa inclinação estava como se estivesse retirada, porém ainda permanecia no meu coração como sempre. Meu mau gênio não havia se extinto; estava apenas oculto como as brasas debaixo das cinzas que as cobrem. Em uma palavra, eu não agia tão mal e com o mesmo descaramento de antes pelo amor que tinha ao meu prudente professor e pela vergonha que me impunham aos demais meninos com suas boas ações, mas não porque não me faltava vontade nem disposição (LIZARDI, 2015, p. 48). 
O que nos tenta provar Lizardi (2015) é que o contexto histórico-social favorece o comportamento do indivíduo, que pode, inclusive, refletir na personalidade, ainda que dependa de atitudes, exatamente como defende Vigotski (apud DANIELS, 2003, p. 170) ao afirmar que:

[...] tudo no comportamento da criança está incorporado e enraizado em relações sociais. Além do que reconhecer que as pessoas constroem sua psicologia ao construir sua atividade social dá-Ihes o poder de alterar sua psicologia pela transformação de sua atividade social.

É isso o que Periquillo fará para ser aceito no grupo. Ainda assim, apesar do bom ambiente do professor com os alunos, não encontramos, no protagonista, a vontade de ser bom por si mesmo, mostrando que talvez o professor tenha pecado na metodologia e no conteúdo apresentado, o que nos faz lembrar do que dissera anteriormente Contreras (2002).

Periquillo não falou exatamente sobre a metodologia do professor, mas, pelas críticas que seguem no decorrer da obra, este não utilizou meios de instigar o aluno e nem causou-lhe a necessidade de buscar e de refletir sobre si e sobre o seu meio, pois o protagonista em nenhum momento cita que foi instigado a pensar tanto no conteúdo quanto na sociedade.

Ao terminar seus estudos, seu pai o obrigou a encontrar um emprego, pois sabia que Periquillo não gostava de estudar; além disso, o pai não possuía condições financeiras para custear o seu segundo grau. Entretanto, por insistência da mãe, Periquillo o cursou. E lá continuou aprendendo muito a pernoitar com os amigos bebendo (era o que the interessava, o que the proporcionava prazer). No entanto, quando se refere aos seus professores e aos métodos, ele escreve que:

[...] ensinavam-nos muita gramática e pouca latinidade. Ordinariamente se contentam os professores em ensinar aos seus discípulos uma multidão de regras que chamam "palitos", com as quais façam algumas pequenas orações e que traduzam o Breviário, o Concilio de Trento, o catecismo de São Pio V, e, por fortuna, alguns pedacinhos da Eneida e Cicerón. Com semelhante método, saem os meninos faladores e não latinistas, como diz o padre Calusanz no seu Dicernimiento de Ingenios. Assim saí eu, e não poderia ter saído melhor: saí com a cabeça cheia de regras, adivinhações, frases e equivoquinhos latinos, mas de inteligência na pureza e propriedade do idioma, nem palavra (LIZARDI, 2015, p. 56). 
O problema que nos apresenta Lizardi é o mesmo que aparece na atualidade: a preocupação com o quantitativo (a nota) e não na pessoa em que está se formando e no que está realmente aprendendo. Vigotski (2011) nos aponta que os conteúdos são, na verdade, ferramentas que nos ajudam a pensar e construir diferentes conhecimentos e que esses mesmos interferem em nossas maneiras de ver e agir no mundo. O conhecimento não é algo que tem que ser gravado; aliás, é isso que desenvolve o cérebro e não a memorização. Ademais, "[...] a experiência pedagógica mostra que o ensino direto de conceitos é pedagogicamente impossível", afirma Vigotski (2011, p. 74). Por conseguinte, não se capta pela memória e sim pelo pensamento, pela interação do conteúdo com o que temos internalizado; ao contrário, o conteúdo será utilizado apenas para reproduzir, sem a valorização de capacidades cognitivas e nem do meio sócio-histórico.

Ao invés de os professores ensinarem a pensar, a refletir sobre os conteúdos, fazendo com que os alunos deem significado a eles, ensinavam-nos a memorizar como se eles fossem louros, papagaios. Mas "[...] na escola, não se é um louro. Não se enche de memória, se forma a inteligência" (RANCIĖRE, 2003, p. 16).

Paulo Freire (2011) nos adverte sobre esse ensino que não influência o aluno a pensar, a ser também autor do seu próprio conhecimento, acabando por não desenvolver a autonomia. Esse ensino bancário ${ }^{3}$, alienante e acrítico "[...] não é apenas uma arma entontecedora de pedagogos, e sim o próprio veículo da ordem social", destaca Rancière (2003, p. 64).

Mas Periquillo retorna às denúncias:

[...] eu passei meu curso de lógica com a mesma velocidade com que passa um raio pela atmosfera: sem deixar sinal de sua carreira, e assim depois de disputar farta e seguidamente sobre as operações do entendimento, sobre a lógica natural, artificial e usual: sobre seu objeto formal e material; sobre os modos de saber sobre se Adão perdeu ou não a ciência pelo pecado (coisa que não se disputa com o demônio); sobre se a lógica é uma ciência ou arte, e sobre trinta mil coisinhas destas, eu fiquei tão lógico como um alfaiate, mas isso sim: muito contente e satisfeito de que seria capaz de concluir os estudos. Ignorava eu que uma árvore se conhece pelos frutos [...]. Eu estava mais oco que uma cabaça, e dizia de boca cheia que era lógico como quase todos os meus condiscípulos (LIZARDI, 2015b, p. 53).

\footnotetext{
${ }^{3} \mathrm{O}$ termo 'bancário' é uma metáfora utilizada por Freire para referir-se a um ensino que apenas se preocupa pela acumulação de conteúdos pelo estudante. Sobre isto, cf. Freire (2011).
} 
Neste trecho Lizardi critica o conteúdo que não gera interesse no aluno ou que não foi planejado de modo a construir-lhes conhecimento. Periquillo ainda segue com mais denúncias: "Teria sido melhor menos regrinhas de conjuntos e alguns exercícios com questões úteis de lógica, [...] e quando se fosse possível de física teórica e experimental” (LIZARDI, 2015b, p. 54). A ilustração demonstra o quanto é falho o ensino que não reconhece os conhecimentos prévios do aluno e o quanto ele é bancário, ainda mais quando levamos em conta o seguinte trecho de Freire (2011, p.33):

Falar da realidade como algo parado, estático, compartimentado e bem-comportado, quando não falar ou dissertar sobre algo completamente alheio à experiência existencial dos educandos vem sendo, realmente, a suprema inquietação desta educação. A sua irrefreada ânsia. Nela, o educador aparece como seu indiscutível agente, como o seu real sujeito, cuja tarefa indeclinável é "encher" os educandos dos conteúdos de sua narração. Conteúdos que são retalhos da realidade desconectados da totalidade em que se engendram e em cuja visão ganhariam significação. A palavra, nestas dissertações, se esvazia da dimensão concreta que devia ter ou se transforma em palavra oca, em verbosidade alienada e alienante.

Esta citação de Freire nos alerta sobre a educação bancária, o que se assemelha à denúncia de Lizardi, personificada em Periquillo.

Ao contrário da educação bancária, encontramos em Vigotski (2011), por exemplo, o aluno que se apropria de novos conhecimentos, transpondo o desenvolvimento empírico para o desenvolvimento científico. Rancière (2003, p. 13), com outro conceito, defende o ensino universal: "[...] aprender alguma coisa e relacioná-la com todo o resto". Contreras (2002) não foge à regra e critica a reprodução do conhecimento. Para ele, o conhecimento deve ser trabalhado pelo professor no intuito de formar cidadãos ativos na sociedade. Neste discurso de Lizardi, Periquillo critica a teoria que não é feita prática e que o vir a saber necessita do vir a viver. Com tantos escritos sobre a educação, principalmente depois de quase 200 anos da publicação desta obra, ainda se questiona: Por que esta educação ainda vigora na educação da contemporaneidade?

Periquillo não foi instigado a procurar conhecimentos ou a refletir sobre eles. Tudo o que seus professores faziam era falar, e ele passivamente ouvia, seja o conteúdo dado ou os conselhos de seu pai. Além do mais, ele nunca criticou seus professores, os conteúdos ou a forma como eram trabalhados, demostrando, assim, que o seu desenvolvimento crítico, até este período, não havia sido desenvolvido. 
Por graça do destino, ele não sabia criticar justamente devido à educação bancária promovida pelos seus professores.

\section{Vida adulta}

Apesar de a escola ser o principal meio para uma pessoa se desenvolver social e cognitivamente, as instituições que Periquillo frequentou não o fizeram sentir qualquer interesse em aprender. Ao contrário, ele seguiu o que é comum a um ser humano alienado: buscar o que Ihe causa prazer. E foi na "malandragem" que ele encontrou prazer, pois era mais instigado a passar a noite se divertindo com os amigos, bebendo e dançando, que acordar cedo e ouvir um professor falando coisas que ele tinha que memorizar sem qualquer relação com a sua vida e que lhe causavam desinteresse, além de nunca ser estimulado pela família a se empenhar na escola.

Segundo Rancière (2003, p.14), "quem ensina sem emancipar, atonta". Logo, o problema não é o tipo de estudante que se formou sem conhecimentos, mas o sujeito que passou pela escola e saiu não ativo na sociedade e na vida profissional. Com a rotina dos estudos passivos, apenas ouvindo, Periquillo não desenvolveu o pensamento crítico ou outra habilidade. Terminou seus estudos "vazio", sem conhecimentos, pois limitava-se a memorizar os conteúdos com intenção de ser aprovado nas avaliações. Notadamente, seus pais não o instigavam. Ao contrario, deixavam-no livre, sem qualquer disciplina. Periquillo não tinha autonomia alguma, pois sempre dependia da opinião dos outros, como sobre qual profissão escolher. Todos, pais e professores, como não favoreceram o desenvolvimento da autonomia de Periquillo, acabaram por atontá-lo.

Ao fim de seus estudos, o pai de Periquillo o obrigou a escolher uma profissão, pois tinha grande receio que se tornasse inútil. Dada a sua idade, temia que após sua morte ninguém lhe ajudasse e que ao fim e a cabo, por necessidade, ele caísse em desgraça:

Sim, Pedro, ser ocioso é inútil; é o pior destino que pode ter o homem, porque a necessidade de sobreviver e o não saber como nem de que os colocam às mãos na porta dos vícios mais vergonhosos. E, por isso, vemos tantos drogados, tantos cafetões de suas próprias filhas e mulheres e tantos ladrões; e por esta causa também se viam e se veem cadeias tão cheias, os presídios, as celas (LIZARDI, 2015, p. 34). 
Mas Periquillo não deu importância a tais conselhos. Ao invés de pensar por si mesmo, foi em busca de um amigo para que the dissesse qual seria a melhor profissão, aceitando o que Ihe foi dito sem perceber seu verdadeiro sentido: ser clérigo.

Voltando a estudar, dessa vez para ser clérigo, Periquillo não pensou na vida que levaria depois de formado, como lhe falou seu amigo, abdicando da formação e, mais uma vez, se entregando à boemia e aos jogos que os outros lhe ensinavam.

Seu pai, depois de descobrir tudo e ouvir as reclamações de um dos seus professores, decidiu de uma vez por todas colocar seu filho em um trabalho, mas a mãe novamente o convenceu a dar um passo atrás e a oferecer outra oportunidade a Periquillo. Com mais dias para pensar no que fazer, foi mais uma vez buscar o amigo para que the dissesse o que seria melhor. $O$ que ocorre, segundo Freire (2013), é que a decisão é característica da autonomia, e ambas precisam ser desenvolvidas no uso cotidiano, dentro e fora da escola. Neste sentido, nota-se, nitidamente, a falta de autonomia de Periquillo.

Tudo, ao fim, ocorreu conforme lhe disse seu pai. Quando esse veio a falecer e sua mãe ficou sem nada, buscou seus parentes que não lhe acolheram, pois não tinha um emprego e, como sempre, recebeu a ajuda de um amigo, dessa vez para sustentar-se dentro da ilegalidade: roubando em jogos. Esse amigo era Januário, um sujeito que sempre estava burlando e que se transformou em seu mestre. Logo, conclui-se que Periquillo sempre apresentou o que Freire (2011) denomina de consciência ingênua diante do mundo, caracterizada pela simplicidade do sujeito interpretar os problemas. Como ele nunca refletiu sobre o que aprendera na escola e na vida, nem se sentia responsável por suas atitudes ou os seus atos, não se podia esperar que fosse diferente.

Cabe-nos recordar que a novela de Lizardi (2015) é picaresca, e nesse tipo de obra, tradicionalmente, um mestre ensina um menino órfão que não sabe nada a como sobreviver. No entanto, Periquillo estudou durante anos; como não sabia nada? Não bastando isso, durante a novela, ele cai em várias armadilhas que são preparadas para tirar proveito dele (praticamente todas). Por conseguinte, como ele nunca buscou respostas para tais situações, nunca refletiu e a escola e seus pais nunca se preocuparam em desenvolver nele tais capacidades, não era esperado que, na vida adulta, de uma hora para outra, ele demonstrasse tais habilidades. 
Podemos perceber, então, a suposta inutilidade do que ele aprendeu durante o período escolar. Ele conseguiu ser aprovado nas provas, mas isso foi insuficiente. Chegou a ir para a cadeia, por uma nova burla de Januário, sem nunca refletir sobre suas atitudes; ao contrario, sempre foi levado pelo destino e pelos caminhos desviantes. Certamente o que pondera o comportamento de Periquillo seja o fato de o seu primeiro professor ter seguido a docência, sem qualquer perfil, e da postura pedagógica do seu segundo: a escola falha, pois nem prepara o aluno para a profissão, nem para a vida.

Algo interessante no decorrer do enredo é o seu arrependimento, o desejo de que seus pais lhe fossem mais rígidos, que seus professores explicassem de forma diferente e que tivesse se dedicado a aprender, como:

[...] se no princípio, se na minha infância, se quando eu não era dono absoluto das minhas paixões, me houvessem corrigido os primeiros ímpetos e não me houvessem lisonjeado com seus mimos, consentimentos e carinhos [...] (LIZARDI, 2015b, p. 182).

Outro momento de arrependimento é narrado quando um homem de bem lhe aconselha na prisão. Ele afirma que "[...] não apenas me socorreu em tudo que pôde, mas me doutrinou com seus conselhos. Ah, se eu o tivesse seguido!" (LIZARDI, 2015b, p. 131).

Para Freire (2003, p. 125), "é sempre assim, o sujeito é sempre responsável por sua deficiência de aprendizagem. O sistema, nunca. É sempre assim, os pobres e miseráveis são os culpados por seu estado precário. São preguiçosos, incapazes". Destarte, espera-se do aluno e do filho que ele pense, por si mesmo, em seu futuro, mas não lhe ensinam a pensar; ao contrário, dificultam-lhes.

No decorrer do enredo, Periquillo comete muitas falhas com a sociedade e inclusive com a própria mãe. Apesar disso, em um hospital, ele tem a sua primeira reação a favor de outra pessoa: um homem bramia por socorro porque estava morrendo, enquanto os enfermeiros fingiam estar dormindo. Periquillo foi tocado por aqueles bramidos e gritou a eles. Percebendo que continuavam a encenação, atirouIhes uma jarra com água, demonstrando que a "maldade" tende a ser uma ausência de conhecimentos e de sensibilização ao próximo, porque o meio molda assim. Neste momento, Periquillo demonstra sinais de autonomia frente a uma necessidade. Entretanto, o que ocorre é um sentimento de autopiedade, refletida no 
outro, pois a falta de conhecimento lhe impede de refletir criticamente sobre o ocorrido e, assim, continua alienado, sem qualquer possibilidade de autonomia.

\section{Sociedade: Comprometimento social e político}

Segundo Contreras (2002), a autonomia do professor é pensada a partir da reflexão e ele não pode tê-la sem pensar, também, na comunidade que cerca o aluno e todo o meio social, dado que ele é responsável pela formação deste cidadão. Por essa razão, necessita de conteúdos que viabilizem a construção do pensamento do aluno sobre o seu meio social. Para Paulo Freire (2013), à formação do cidadão são indispensáveis qualidades e virtudes, as quais são produzidas no meio ou dentro da escola, seja por meio de conteúdos, discussões, reflexões ou influências dos professores.

Se, por um lado, o tipo de ensino que não desenvolve a autonomia do aluno e a sua reflexão acaba por torná-lo "malandro" e dependente do meio, por outro, encontramos profissionais individualizados e que não trabalham em comunhão para o bem de todos. Os mesmos que aprenderam a estudar por notas são os que aprenderam a trabalhar unicamente pelo dinheiro. O que foi estudado e memorizado na escola não serviu para sensibilizá-lo ao exercício pleno da cidadania: serviu para passar nas provas e nada mais.

Quando sai às ruas, Periquillo faz inúmeras denúncias sobre a população e os profissionais: por culpa de Januário, para em um hospital, e como já dito, deparase com um homem morrendo enquanto os enfermeiros dormiam em horário de trabalho e fingiam não ouvir seus gritos e médicos que atendem em torno de 60 pessoas em uma mesma sala e prescrevem a mesma medicação a todos. Quase medicando Periquillo erroneamente, utilizaram, como desculpa, o fato de que ele estava no lugar errado. Além disso, na prisão, cobram-Ihe propina. Um escrivão abusa de seu poder e inocenta um homem, colocando a culpa sobre um inocente por causa da bela irmã do criminoso. Um cabelereiro que deveria ensinar a profissão a um menino usa-o como empregado. E por aí seguem suas denúncias.

Levando em conta a análise dos discursos presentes na obra, Lizardi nos mostra profissionais despreocupados com o seu meio, justamente pela reprodução do conteúdo sem relação com a vida dos alunos e sem a preocupação na sensibilização social destes, o que inviabilizava a participação da sociedade na sua 
própria melhoria, pois os alunos que pensavam apenas nas suas notas tomaram-se profissionais que se importam apenas com o dinheiro.

A nosso ver, o ensino bem estruturado não apenas funciona como mediador do conhecimento do sujeito, mas sensibiliza-o perante si e o outro, desenvolvendoIhe a autonomia.

\section{Considerações Finais}

Analisando os dois tomos da obra Periquillo Sarniento, percebemos discursos voltados a uma inércia presente em boa parte da educação, pois o que a literatura normalmente denuncia é o momento presente, o que tem que ser enfrentado e modificado. Todavia, as denúncias de Lizardi (2015) chegam à atualidade, o que pode ser verificado, principalmente, nas palavras de Freire ao criticar a mesma educação no qual o aluno é passivo e o conteúdo tem de ser memorizado.

Por outro lado, compreendemos a principal denúncia de Lizardi (2015) ao elaborá-la dentro de uma novela picaresca. Tradicionalmente, neste tipo de obra, o personagem principal, um menino órfão e abandonado, é ensinado por um mestre a como lidar com a vida, porém, na novela de Lizardi (2015), o protagonista é um adulto que não possui conhecimentos e nem sabe buscá-los por si só.

Esse tipo de dependência, compreendida pelo aporte dos teóricos aqui estudados, deve-se ao fato de que a autonomia precisa de um ambiente que favoreça o desenvolvimento do sujeito: normalmente quando se facilita muito para o filho ou para o aluno, dificultamos a construção dessa capacidade. O conteúdo ministrado e a forma como é apresentado também contribui fortemente para o desenvolvimento ou não da autonomia e das outras capacidades necessárias à formação integral do sujeito, influenciando não apenas o ser humano que será formado para e pela sociedade.

Quanto aos seus mestres, na obra, não enfatizam os conteúdos que sensibilizam o aluno frente à sociedade. Ao contrário, fazem com que o aluno mantenha-se afastado do ambiente social. Por não pensarem nos outros e apenas em si mesmos, os mestres acabam alienadamente colaborando para a manutenção do status quo.

Por fim, ainda sob a ótica do professor, os discursos aqui analisados demostram que não basta possuir conhecimento e um bom relacionamento com os 
alunos, é necessário saber ensinar-Ihes e instigar-Ihes a vontade de aprender, seja pelo prazer presente nas tarefas ou nas dificuldades que elas apresentem, seja pelos novos conhecimentos socializados pelo docente, facilitando-lhes a capacidade de reflexão para contribuir com o desenvolvimento de sua autonomia.

\section{Referências}

CONTRERAS, José. A autonomia do professor. Trad. Sandra Trabucco Valenzuela. São Paulo: Cortez, 2002.

DANIELS, Harry. Vygotsky e a pedagogia. Trad. Milton Camargo Mota. São Paulo: Edição Loyola, 2003.

FREIRE, Paulo. Pedagogia da autonomia. 44.ed. Rio de Janeiro: Paz e Terra, 2013. . Pedagogia do oprimido. 50.ed. Rio de Janeiro: Paz e Terra, 2011.

; HORTON, Myles. O caminho se faz caminhando: conversas sobre educação e mudança social. 4.ed. Petrópolis, RJ: Vozes, 2003.

GARCÍA, Jesús Hernández. Fernández de Lizardi y la necesidad ilustrada de la educación civil y política. Fundación Dialnet, Universidad de la Rioja, 2010. Disponível em: <https://dialnet.unirioja.es/descarga/articulo/3214259.pdf>. Acesso em: 12 jun. 2016.

LIZARDI, José Joaquín Fernándes de. El Periquillo Sarniento: Tomo I. Alicante: Biblioteca Virtual Miguel de Cervantes, 2001a. Disponível em: <https://goo.gl/PxcFHX>. Acesso em: 12 jun. 2015.

- El Periquillo Sarniento: Tomo II. Alicante: Biblioteca Virtual Miguel de Cervantes, 2001b. Disponível em: <https://goo.gl/3IWcBn>. Acesso em: 12 jun. 2015 .

MORALES, Pedro. A relação professor-aluno: o que é, como se faz. 9.ed. São Paulo: Edição Loyola, 2009.

PÍCARO. In: Dicionário Priberam da Língua Portuguesa [online], 2008-2013. Disponível em: <http://www.priberam.pt/dlpo/p\%C3\%ADcaro>. Acesso em: 31 out. 2016.

PIMENTA, S. G. (Org.). Professor reflexivo no Brasil: gênese e crítica de um conceito. 7.ed. São Paulo: Cortez, 2012.

RANCIĖRE, Jacques. El maestro ignorante: cinco lecciones sobre la emancipación intelectal. Tad. Núria Estrach. Barcelona: Laertes, 2003.

VARGAS, F. A. (Org.). Poesia espanhola: das origens à guerra civil. São Paulo: Hedra, 2009. 
$\mathbb{B}_{\text {๖issei }} \mathcal{A}$

VASCONCELOS, M. C. C. Igreja e educação: a influência da catequese nos primórdios da literatura pedagógica. In: LEMOS, M. T. T. B. (Org.). Religião, violência e exclusão. Rio de Janeiro: 7letras, 2006, p. 71-96.

VICENTE, Alonso Zamora. ¿Qué es la novela picaresca? Alicante: Biblioteca Virtual Miguel de Cervantes, 2002. Disponível em: <https://goo.gl/jkdKBb>. Acesso em: 15 out. 2016.

VIGOTSKI, L. S. A formação social da mente. 7.ed. São Paulo: Martins Fontes, 2011. 